\title{
AN ASSESSMENT OF THE PHYSICAL ACTIVITY OF ADULTS RESIDING IN THE ŚWIĘTOKRZYSKIE REGION
}

\author{
ANDRZEJ JOPKIEWICZ ${ }^{1}$, JACEK GAWRON ${ }^{2}$ \\ ${ }^{1}$ Jan Kochanowski University in Kielce, Faculty of Pedagogy and Art, Department of Auxology \\ ${ }^{2}$ Kielce University of Technology, Sport Centre
Mailing address: Andrzej Jopkiewicz, Faculty of Pedagogy and Art, Department of Auxology, 11 Krakowska Street, 25-029 Kielce, tel.: + 4841 3496763, fax: + 48413496782 ,
e-mail: ajopkiewicz@poczta.onet.pl

\begin{abstract}
Introduction. The aim of the study is to assess the physical activity of adults residing in the Świętokrzyskie region in Poland with relation to age, gender, and socioeconomic factors such as the level of education, place of residence, and financial situation. Material and methods. The survey questionnaire used to assess physical activity was prepared by the Department of Auxology of Jan Kochanowski University in Kielce. The study group involved a total of 1,032 persons, aged 20-59 years, including 517 women and 515 men. The results of the study were subjected to statistical analysis. Two tests were carried out to determine the correlations between variables: Spearman's rank correlation coefficient was calculated and the nonparametric chi-square test $\left(\mathrm{x}^{2}\right)$ was used. Results. It was found that the leisure-time physical activity of the adults residing in the Świętokrzyskie region who participated in the study was insufficient and remained at a low level. Particularly alarming is the fact that a low level of leisure-time physical activity was found for young persons, both male and female, aged 2039 years. This low level of activity also prevailed in the older age groups. Apart from age, gender, and the level of education, the place of residence and financial situation significantly impacted the physical activity of the adults. Conclusions. It was observed that the physical activity of men and women aged 20-59 years in their leisure time was the greater the bigger the size of the agglomeration they resided in, the higher their level of education, and the better their financial situation.
\end{abstract}

Key words: physical activity, socioeconomic factors, adults

\section{Introduction}

Physical activity is the basis of a healthy lifestyle and is strongly associated with other components of this lifestyle such as nutrition, sleep, personal hygiene, dealing with stress, abstinent behaviour, optimism, etc. It fundamentally influences health and well-being. Hence, movement accompanies us throughout our lives; thanks to it we develop physically, explore our surroundings, learn the limits of our capabilities, and work professionally.

Physical activity is treated not only as one of the most important components of human health but also as its positive indicator [1, 2]. The term "physical activity" usually refers to body movement caused by the contraction of skeletal muscles that significantly raises energy expenditure. When it comes to health, it is best when this energy expenditure, above the basal metabolic rate, amounts to approximately 3,000 kcal per week, taking into account all leisure-time activities, exercise, sports, occupational work, and other everyday activities [3, 4].

The low level of physical activity of members of modern society is a relevant social problem because the 21st century is a period of technological progress that has caused us to spend most of the time in sitting position. Our work has become more monotonous, we are increasingly physically inactive, and we live in a constant rush. The rapid pace of social changes has led to a reduction in leisure-time physical activity and a gradual decline in psychological resilience. However, providing a precise definition of the level of physical activity in population studies is very difficult; hence, some estimation needed to be made. The aim of this study is to attempt to assess the physical activity of adults residing in the Świętokrzyskie region with relation to age, gender, and socioeconomic factors such as the level of education, place of residence, and financial situation.

\section{Material and methods}

The survey study was conducted in the Świętokrzyskie region in the spring of 2010 based on purposive random sampling, with priority given to the following randomly selected facilities:

- universities in Kielce that offer part-time courses,

- units of the Świętokrzyskie Vocational Education Centre (ŚZDZ).

The survey questionnaire used to assess physical activity was prepared by the Department of Auxology of Jan Kochanowski University in Kielce. The questions covered preferences related to lifestyle, ways of spending leisure time, leisure-time physical activity, and walking activity. The validation of the questionnaire showed that the reliability coefficient (Cronbach's alpha) amounted to 0.81 ; therefore, the questionnaire could be used in cross-sectional studies [5].

The study involved a total of 1,032 persons, aged 20-59 years, including 515 men and 517 women who were classified according to different features. First of all, the participants were divided into four age groups: persons aged 20-29, 30-39, 40-49, and 50-59 years, with similar average ages of the men and women in the groups, which were $22.6,34.9,44.8$, and 54.4 , respectively 
(tab. 1). The choice of these age cohorts made it possible to perform various comparisons.

Table 1. Age of the participants of the study

\begin{tabular}{|c|c|c|c|c|c|c|c|}
\hline \multirow{2}{*}{$\begin{array}{c}\text { Age } \\
\text { group }\end{array}$} & \multicolumn{2}{|c|}{ Women } & \multicolumn{2}{c|}{ Men } & \multicolumn{2}{c|}{ Total } & $\begin{array}{c}\text { Average } \\
\text { age } \\
\text { in the } \\
\text { group }\end{array}$ \\
\cline { 2 - 8 } & $\mathbf{N}$ & $\%$ & $N$ & $\%$ & $N$ & $\%$ & x \\
\hline $20-29$ & 165 & 54.8 & 136 & 45.2 & 301 & 29.2 & 22.6 \\
\hline $30-39$ & 122 & 51.0 & 117 & 49.0 & 239 & 23.2 & 34.9 \\
\hline $40-49$ & 116 & 45.9 & 139 & 44.1 & 255 & 24,7 & 44.8 \\
\hline $50-59$ & 114 & 48.3 & 122 & 51.7 & 236 & 22.9 & 54.4 \\
\hline Total & 517 & 50.1 & 515 & 49.9 & 1032 & 100.0 & 39.2 \\
\hline
\end{tabular}

As far as education is concerned, the subjects were divided into four groups depending on whether they had: primary and basic vocational education (these two groups were joined due to a small number of respondents with primary education); secondary education; incomplete higher education, which was comprised of various forms of post-secondary education; or higher education. The group consisting of persons with secondary education was the most numerous (tab. 2).

Table 2. Level of education of the participants of the study

\begin{tabular}{|l|c|c|c|c|c|c|}
\hline \multirow{2}{*}{ Education } & \multicolumn{2}{|c|}{ Women } & \multicolumn{2}{c|}{ Men } & \multicolumn{2}{c|}{ Total } \\
\cline { 2 - 7 } & $\mathbf{N}$ & $\%$ & $\mathbf{N}$ & $\%$ & $\mathbf{N}$ & $\%$ \\
\hline $\begin{array}{l}\text { Primary and } \\
\text { basic vocational }\end{array}$ & 151 & 29.2 & 151 & 29.3 & 302 & 29.2 \\
\hline Secondary & 218 & 42.4 & 171 & 33.2 & 390 & 37.8 \\
\hline $\begin{array}{l}\text { Incomplete } \\
\text { higher education }\end{array}$ & 56 & 10.8 & 84 & 16.3 & 140 & 13.6 \\
\hline Higher & 91 & 17.6 & 109 & 21.2 & 200 & 19.4 \\
\hline Total & 517 & 100.0 & 515 & 100.0 & 1032 & 100.0 \\
\hline
\end{tabular}

As for the urbanisation variable, three social environments were distinguished that constituted the respondents' permanent place of residence, i.e. rural areas, small towns, and large cities (having over 100,000 inhabitants). Persons living in rural areas represented the largest percentage of respondents (tab. 3). It should be noted that the results of the study for the place of residence largely reflect the structure of the population of the Świetokrzyskie region. When it comes to the respondents' financial situation, the study group was strongly dominated by persons who declared their financial situation was average, and a similar percentage of the study participants described their financial situation as good and below average.

Table 3. Place of residence of the participants of the study

\begin{tabular}{|l|c|c|c|c|c|c|}
\hline \multirow{2}{*}{$\begin{array}{c}\text { Place } \\
\text { of residence }\end{array}$} & \multicolumn{2}{|c|}{ Women } & \multicolumn{2}{c|}{ Men } & \multicolumn{2}{c|}{ Total } \\
\cline { 2 - 7 } & $\mathbf{N}$ & $\%$ & N & $\%$ & N & $\%$ \\
\hline Rural area & 257 & 49.7 & 180 & 35.0 & 437 & 42.3 \\
\hline Small town & 158 & 30.6 & 179 & 34.8 & 337 & 32.7 \\
\hline Large city & 102 & 19.7 & 156 & 30.3 & 258 & 25.0 \\
\hline Total & 517 & 100.0 & 515 & 100.0 & 1032 & 100.0 \\
\hline
\end{tabular}

The results in the form of figures and percentages were tested statistically. To ensure a higher level of reliability, two tests were used to determine correlations between variables: Spearman's rank correlation coefficient and the nonparametric chi-square test (x2) [6]. All the calculations were performed using STATISTICA 8.0 and statistical significance was determined at the level of $\mathrm{p}<0.01$ and $\mathrm{p}<0.05$.

\section{Results}

The women who participated in the study declared they had a considerably lower level of physical activity than did the men (fig. 1); both on the basis of the chi-square test and Spearman's rank correlation, significant correlations were found with regard to gender $(p<0.01)$. In the group of women, age did not determine physical activity and the percentages of women declaring different levels of leisure-time physical activity in specific age groups were at a similar level (fig. 2). Moreover, it was found that the declared level of leisure-time physical activity of the men declined steadily with age (fig. 3).

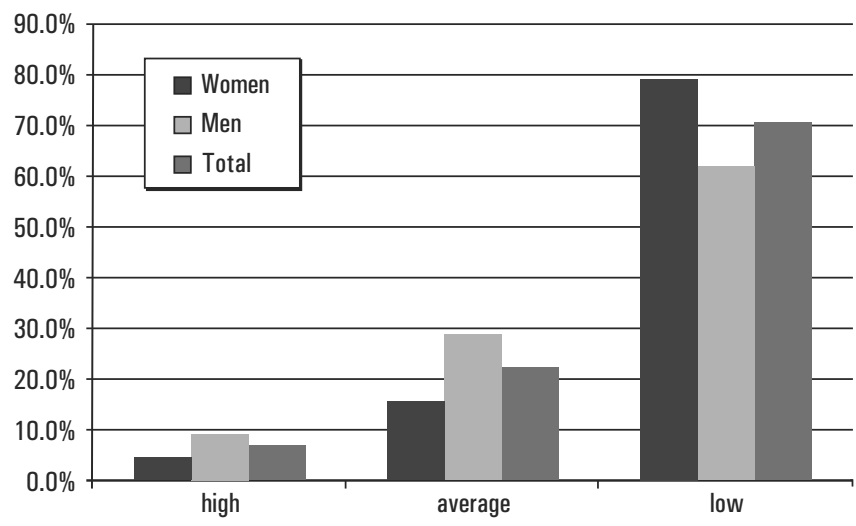

Figure 1. Level of physical activity of the participants of the study (\%)

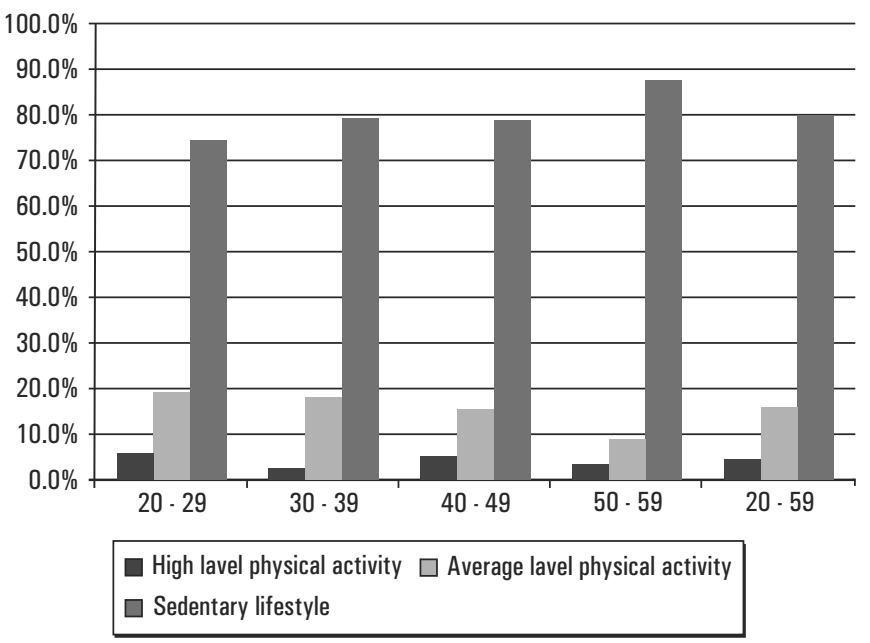

Figure 2. Percentage of women characterised by particular levels of leisure-time physical activity in specific age groups 


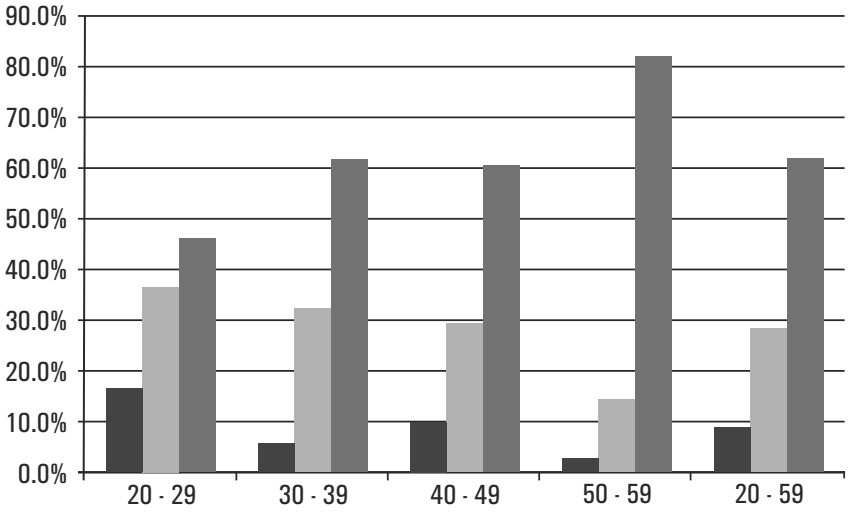

$\square$ High lavel physical activity $\square$ Average lavel physical activity $\square$ Sedentary lifestyle

Figure 3. Percentage of men characterised by particular levels of leisure-time physical activity in specific age groups

Another type of data that were gathered was the number of times (days) in a week (4 times or more, 1-3 times, or none) [7] in which the study participants walked on foot for $60 \mathrm{~min}$ utes. Based on the results, the women were determined to have a higher level of walking activity than the men (fig. 4).

More than half of the men and women who participated in the study declared that in everyday life they prefer average physical activity in their leisure time and every third woman and every fourth man preferred a sedentary lifestyle (fig. 5).

The women preferred watching television and videos or listening to the radio and using a computer, which ranked second, in their leisure-time. As for the men, their most favourite leisuretime activity was using a computer and then watching television and videos or listening to the radio. Both the women and men spent the same amount of time sitting still mainly in front of the TV or a computer (fig. 6).

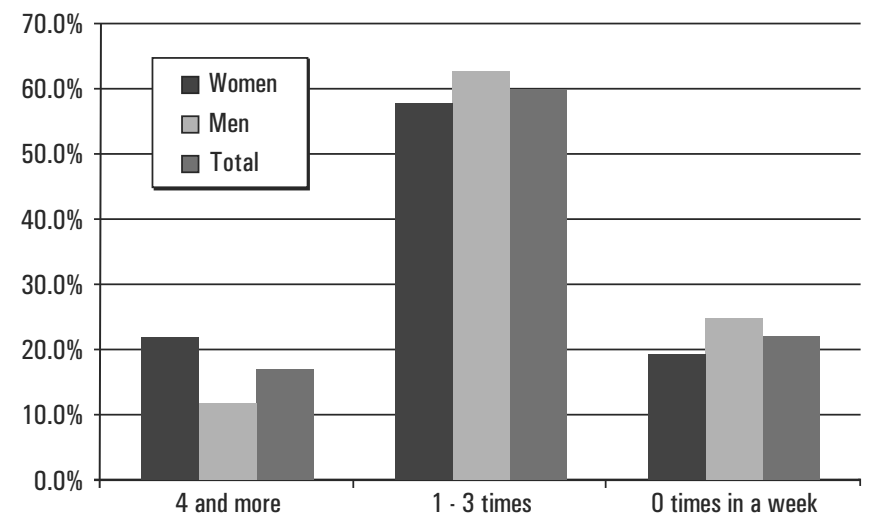

Figure 4. Percentage of participants declaring they walked for 60 minutes a particular number of times during the week (\%)

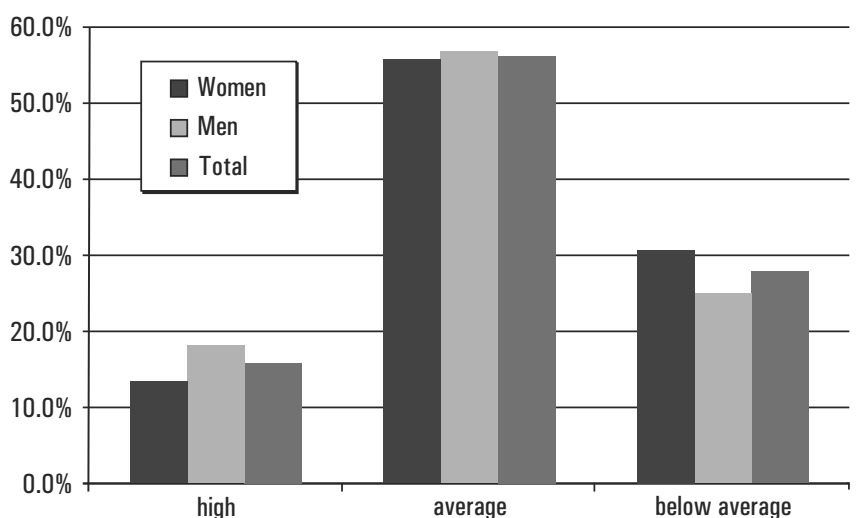

Figure 5. Percentage of participants declaring particular levels of physical activity in their everyday life

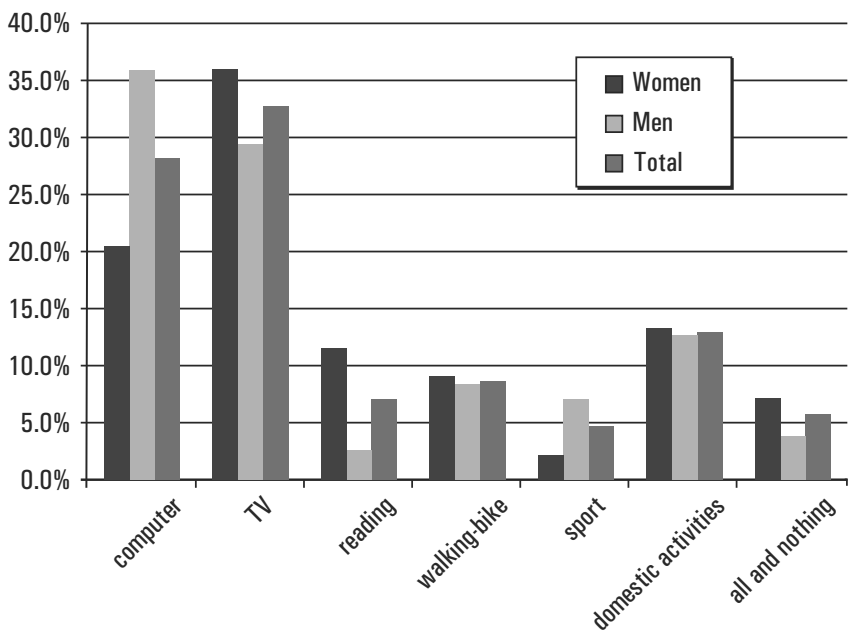

Figure 6. Percentage of participants declaring they preferred particular ways of spending their leisure time

The results of the chi-square test revealed a relevant correlation between the level of education, place of residence, and financial situation of both the men and women and their leisure-time physical activity. However, only in the women age was not a factor strongly influencing physical activity (tab. 4).

Spearman's rank correlation coefficients also indicated that there was a correlation between leisure-time physical activity and not only age but also the level of education and financial situation of the men and women studied. These were statistically significant correlations with a positive sign: the level of leisure-time physical activity was directly proportional to the level of education and financial situation of the adults (tab. 5). Only the place of residence did not impact their physical activity, which seems quite understandable.

Table 4. Results of the chi-square independence test indicating the correlations between leisure-time physical activity and age and socioeconomic factors

\begin{tabular}{|l|c|c|c|c|c|c|}
\hline \multirow{2}{*}{\multicolumn{1}{c|}{ Variables }} & \multicolumn{3}{c|}{ Women } & \multicolumn{3}{c|}{ Men } \\
\cline { 2 - 7 } & $x^{2}$ & $f_{1}$ & $p$ & $x^{2}$ & $f_{1}$ & $p$ \\
\hline Age & 9.6999 & 6 & 0.1378 & 40.1239 & 6 & $\mathbf{0 . 0 0 0 0}$ \\
\hline Level of education & 13.183 & 6 & $\mathbf{0 . 0 4 0 2}$ & 43.4736 & 6 & $\mathbf{0 . 0 0 0 0}$ \\
\hline Place of residence & 18.8736 & 4 & $\mathbf{0 . 0 0 0 6}$ & 9.5684 & 4 & $\mathbf{0 . 0 4 8 3}$ \\
\hline Financial situation & 14.8295 & 4 & $\mathbf{0 . 0 0 5 1}$ & 31.4056 & 4 & $\mathbf{0 . 0 0 0 0}$ \\
\hline
\end{tabular}

* - Statistically significant differences and correlations are in bold. 
Table 5. Spearman's rank correlation coefficients indicating the correlations between leisure-time physical activity and age and socioeconomic factors

\begin{tabular}{|l|c|c|c|c|c|c|}
\hline \multirow{2}{*}{ Variables } & \multicolumn{3}{c|}{ Women } & \multicolumn{3}{c|}{ Men } \\
\cline { 2 - 7 } & $\boldsymbol{R}$ & $\boldsymbol{t}$ & $\boldsymbol{p}$ & $\boldsymbol{R}$ & $\boldsymbol{t}$ & $\boldsymbol{p}$ \\
\hline Age & 0.1071 & 2.4383 & $\mathbf{0 . 0 1 5 1}$ & 0.2440 & 5.7932 & $\mathbf{0 . 0 0 0 0}$ \\
\hline Level of education & 0.1015 & 2.3090 & $\mathbf{0 . 0 2 1 4}$ & 0.2525 & 5.9100 & $\mathbf{0 . 0 0 0 0}$ \\
\hline Place of residence & -0.5590 & -1.2600 & 0.2056 & -0.0635 & -1.4400 & 0.1502 \\
\hline Financial situation & 0.1466 & 3.3547 & $\mathbf{0 . 0 0 0 9}$ & 0.2212 & 5.1374 & $\mathbf{0 . 0 0 0 0}$ \\
\hline
\end{tabular}

* - Statistically significant differences and correlations are in bold.

Regarding walking activity, the results of the chi-square test indicated that in the women it correlated not only with age but also with the level of education and place of residence. On the other hand, in men only age was not a factor that influenced their walking activity (tab. 6). This confirms the observations mentioned above concerning small differences in walking activity between men in different age groups.

Table 6. Results of the chi-square test indicating the correlations between walking activity and age and socioeconomic factors

\begin{tabular}{|l|c|c|c|c|c|c|}
\hline \multirow{2}{*}{\multicolumn{1}{c|}{ Variables }} & \multicolumn{3}{c|}{ Women } & \multicolumn{3}{c|}{ Men } \\
\cline { 2 - 7 } & $\boldsymbol{x}^{2}$ & $\boldsymbol{f}_{1}$ & $\boldsymbol{p}$ & $\boldsymbol{x}^{2}$ & $\boldsymbol{f}_{1}$ & $\boldsymbol{p}$ \\
\hline Age & 7.2366 & 4 & $\mathbf{0 . 0 0 0 0}$ & 2.3960 & 4 & 0.6633 \\
\hline Level of education & 44.9659 & 6 & $\mathbf{0 . 0 0 0 0}$ & 45.8381 & 6 & $\mathbf{0 . 0 0 0 0}$ \\
\hline Place of residence & 13.7974 & 4 & $\mathbf{0 . 0 0 7 9}$ & 18.6477 & 4 & $\mathbf{0 . 0 0 0 9}$ \\
\hline Financial situation & 5.1315 & 4 & 0.2740 & 33.1246 & 4 & $\mathbf{0 . 0 0 0 0}$ \\
\hline
\end{tabular}

* - Statistically significant differences and correlations are in bold.

Spearman's rank correlation coefficients also indicated that there was a correlation between the place of residence, level of education, and walking activity of the women. This means the larger the agglomeration which was the permanent place of residence and the higher the level of education were, the greater the level of walking activity of the women was. As for the men, all of the analysed variables correlated with the level of walking activity. However, for the men's financial situation this correlation was inversely proportional, which meant that the better their financial situation was, the lower their level of walking activity was (tab. 7).

Table 7. Spearman's rank correlation coefficients indicating the correlations between walking activity and age and socioeconomic factors

\begin{tabular}{|l|c|c|c|c|c|c|}
\hline \multirow{2}{*}{ Variables } & \multicolumn{3}{c|}{ Women } & \multicolumn{3}{c|}{ Men } \\
\cline { 2 - 7 } & $\boldsymbol{R}$ & $\boldsymbol{t}$ & $\boldsymbol{p}$ & $\boldsymbol{R}$ & $\boldsymbol{t}$ & $\boldsymbol{p}$ \\
\hline Age & 0.0523 & 0.8782 & 0.2370 & 0.0254 & 0.5721 & 0.5674 \\
\hline Level of education & 0.1686 & 3.8710 & $\mathbf{0 . 0 0 0 1}$ & 0.2831 & 6.6472 & $\mathbf{0 . 0 0 0 0}$ \\
\hline Place of residence & 0.1142 & 2.6000 & $\mathbf{0 . 0 0 9 5}$ & 0.1880 & 4.3090 & $\mathbf{0 . 0 0 0 0}$ \\
\hline Financial situation & -0.0490 & -1.1050 & 0.2679 & -0.2182 & -5.0340 & $\mathbf{0 . 0 0 0 0}$ \\
\hline
\end{tabular}

\footnotetext{
* - Statistically significant differences and correlations are in bold.
}

\section{Discussion}

In cross-sectional studies physical activity is usually assessed using different types of questionnaires because they do not need specialised equipment, laboratory conditions, or gathering respondents in places where the research is carried out.
Such questionnaires can be used regardless of a person's age, gender, or health condition. In this study a group administered survey was conducted, using a questionnaire with a sufficient reliability coefficient, and one of the authors took part in administering it.

Comparing physical activity in different populations and establishing its determining factors and causes of differences between subjects is very difficult. This is problematic due to conceptual and terminological differences, the variety of tools used to assess physical activity, and the different kinds of recommendations made.

It is worth mentioning at this point that research has found that health benefits can be achieved by persons who undertake regular moderate-intensity physical activity [8]. Haskell et al. [8] emphasise that the total sum of physical activity should amount to at least 200 kilocalories per day, hence every adult person should accumulate 30 minutes or more of moderate-intensity physical activity on most, or preferably all, days of the week. Many other recommendations have been offered with regard to daily physical activity. A team of specialists set up by the Centers for Disease Control and Prevention and the American College of Sports Medicine in the United States stresses that "to maintain and promote health, all adults need moderate-intensity physical activity for a minimum of 30 minutes on five days each week or vigorous-intensity physical activity for a minimum of 20 minutes on three days each week" [9].

The recommended daily 30 minutes of physical activity can be accumulated during shorter periods. Therefore, the intensity is not as important as the volume of activity and thus the general energy expenditure of the organism. This may comprise the physical activity involved in day-to-day activities, e.g. climbing the stairs instead of using a lift, intense walking instead of travelling a short distance by car, riding a stationary bike while watching TV, gardening, domestic chores, dancing, etc. The intensity of such effort has to be the same as that of brisk walking. It is recommended that persons who undertake such physical activity should perform it frequently and for a long time [9].

Physical activity plays a significant role in health prevention $[2,10,11]$. Unfortunately, the amount of physical recreation performed by Polish people is not satisfactory, the main reason for this being the lack of time, as stated by respondents of surveys [12]. Physical activity is one of the most important factors influencing health, life expectancy, and well-being. The lack of physical activity is one of the main reasons for the incidence of the so-called diseases of civilisation, among which cardiovascular diseases, obesity, diabetes, and cancer are the most common [11, 13, 14, 15, 16].

The research of Drygas et al. [7] that was carried out in several European countries shows that while the inhabitants of Finland and Spain are among those who undertake a high level of physical activity the most willingly, as these persons account for $30.2 \%$ and $23.7 \%$ of the population, respectively; however, in Poland this figure is only $6.4 \%$. Recreational physical activity is frequently engaged in by $29.9 \%$ of Finns, $19.9 \%$ of Germans, and only $5.9 \%$ of Poles. Similar results were obtained in the current study, and they are directly comparable to those of the research conducted by Drygas et al. [7], since a similar categorisation of physical activity was used in this study.

The alarming finding that a high percentage of adults residing in the Świętokrzyskie region have a sedentary lifestyle corresponds with the results of the research of Drygas et al. [7]. The study found that $70.0 \%$ of Poles did not undertake any physical activity and in the current study this percentage was $70.5 \%$ (79.1\% of the women and $61.9 \%$ of the men). A sedentary lifestyle was preferred by a definitely higher percentage of women than men and these differences were more visible in older age groups.

The men were characterised by a slightly higher level of 
physical activity than the women, with a sharper tendency for this activity to be reduced in older age groups. As 70.5\% of all the persons surveyed were characterised by a sedentary lifestyle, the current research can be seen as evidence confirming that an overwhelming number of Poles do have such a lifestyle. On the other hand, some more optimistic results were obtained concerning walking activity, because $16.9 \%$ of the respondents exhibited a high level of this activity (they walked 4 and more times a week for more than 1 hour), a result which is notably different from the one obtained by Drygas et al. [7] in this respect: while $22.1 \%$ of our respondents did not engage in walking activity, this figure was as high as $95.1 \%$ in the research of Drygas et al. [7].

Preference for a high level of physical activity in everyday life was declared by $15.7 \%$ of the participants of the study, which was only to a small extent confirmed by their answers to other questions. The high percentage $(56.4 \%)$ of persons declaring average physical activity also appears to be overestimated. The most favourite leisure-time activity of the participants (approximately 30 percent of them), as is the case with the majority of Poles, was watching TV or listening to the radio and using the computer, which corresponds with the high percentage of adults having a sedentary lifestyle.

The small interest in sport and recreation is reflected in the low usage of the sports-recreational base available in the Świętokrzyskie region by its inhabitants. The vast majority (61.1\%) of the participants of this study did not use sports equipment at all, $25.7 \%$ used it sporadically, and only $12.9 \%$ of them declared they used it systematically. It is worth mentioning that a study conducted by the Polish Public Opinion Research Centre (CBOS) [17] showed that the sports-recreational base in Poland was used the most frequently by young people (78\%), by persons residing in big cities (68\%), by persons who were better educated (79\%), and those who were in a better financial position (61\%).

\section{Conclusions}

1. The leisure-time physical activity of men and women residing in the Swiętokrzyskie region is not sufficient and remains a low level. Alarming is also the fact that young people, both women and men aged 20-39 years, were characterised by a low level of leisure-time physical activity.

2. The inhabitants of the Świętokrzyskie region who participated in the study declared they engaged in a significant amount of walking activity, because almost $17 \%$ of both men and women walked to work from home or home from work for more than 60 minutes every day. Only every fourth person declared a lack of walking activity.

3. Socioeconomic factors had a significant impact on the leisure-time physical activity of the adult female and male participants of the study. The leisure-time physical activity of women and men aged 20-59 years was the greater the larger the agglomeration they lived in, the higher their level of education, and the better their financial situation.

4. Age had a significant influence on the leisure-time physical activity of the men, and it impacted the walking activity of the women only to a small extent. This is arguably related to a very low level of physical activity of the women and also to adverse changes which have occurred in modern civilisation, causing a reduction of both leisure-time physical activity and walking activity of different persons already at an early age.

\section{Literature}

1. Jopkiewicz A., Suliga E. (2011). Biomedical basis of development and education. Radom-Kielce: ITE-PIB. [in Polish]

2. Jopkiewicz A., Wróblewski P. (2010). Physical activity and health. In: A. Jopkiewicz (ed.), Auxology and health promotion (pp. 259-279). Kielce-Warszawa: KTN i ALMAMER. [in Polish]

3. Ronikier A. (2008). Physiology of sport, physiotherapy and recreation. Warszawa: COS. [in Polish]

4. Howley E.T., Franks B.D. (2007). Fitness Professional's Handbook. Champaign, Illinois: Human Kinetics.

5. Niemierko B. (1999). Educational measurement. Warszawa: WSiP. [in Polish]

6. Ferguson A.G. (1999). Statistical analysis in psychology and pedagogy. Warszawa: PWN. [in Polish]

7. Drygas W., Skiba A., Białecki W., Puska. P. (2002). Assessment of physical activity of populations of 6 European countries under the ,Bridging East-West Health Gap” project. Medycyna Sportowa 18(5), 169-174.

8. Haskell W.L., Lee I.M., Pate R.R., Powell K.E., Blair S.N., Franklin B.A. et al. (2007). Physical activity and public health: updated recommendation for adults from the American College of Sports Medicine and the American Heart Association. Medicine and Science in Sports and Exercise 39(8), 14231434.

9. Pate R.R., Pratt M., Blair S.N., Haskell W.L., Macera C.A., Bouchard C. et al. (1995). Physical activity and public health. A recommendation from the Centers for Disease Control and Prevention and the American College of Sports Medicine. Journal of the American Medical Association 273, 402-407.

10. Sorenson J.B., Skovgaard T., Puggard L. (2006). Exercise on prescription in general practice: a systematic overview. Scandinavian Journal of Primary Health Care 24, 69-74.

11. Szeklicki R. (2007). Habitual physical activity among men over 60 years old: morphologic and metabolic consequences and social determinants. Poznań: AWF. [in Polish]

12. Drygas W., Piotrowicz R., Jegier A., Kopeć G., Podolec P. (2008). Physical activity among healthy people. Forum Profilaktyki 3, 1-3. [in Polish]

13. Warburton D., Nicol C.W., Bredin S. (2006). Prescribing exercise as preventive therapy. Canadian Medical Association Journal 174, 961-974.

14. Corbin C.B. (2002). Physical activity for everyone: What every physical educator should know about promoting lifelong physical activity. Journal of Teaching in Physical Education 21, 128-144.

15. Mynarski W., Rozpara M., Królikowska B., Puciato D., Graczkowska B. (2012). Qualitative and quantitative aspects of physical activity. Opole: Politechnika Opolska. [in Polish]

16. Corbin C.B., Welk G.J., Corbin W.R., Welk K.A. (2007). Fitness and Wellness. Shape, agility, health. Poznań: Zysk i Spółka. [in Polish]

17. Centrum Badania Opinii Społecznej. (2005). Culinary tastes, consumption habits and consumer behaviours of Poles. Warszawa: CBOS. [in Polish]

Submitted: October 21, 2014

Accepted: May 13, 2015 